Abraham, R., Aier, S., Winter, R.: Two Speeds of EAM - A Dynamic Capabilities Perspective, Aier, S., Ekstedt, M., Matthes, F., Proper, E., Sanz, J. (Eds.): Trends in Enterprise Architecture Research and Practice Driven Research on Enterprise Transformation, Barcelona, 23.10.2012, Springer, Berlin, Heidelberg, LNBIP 131, 2012, pp. 111-128., DOI: $10.1007 / 978-3-642-34163-2 \_7$

\title{
Two Speeds of EAM-A Dynamic Capabilities Perspective
}

\author{
Ralf Abraham, Stephan Aier, Robert Winter \\ Institute of Information Management, University of St. Gallen, Mueller-Friedberg-Strasse 8, \\ 9000 St. Gallen, Switzerland \\ \{Ralf.Abraham, Stephan.Aier, Robert.Winter\}@unisg.ch
}

\begin{abstract}
We discuss how enterprise architecture management (EAM) supports different types of enterprise transformation (ET), namely planned, proactive transformation on the one hand and emergent, reactive transformation on the other hand. We first conceptualize EAM as a dynamic capability to access the rich literature of the dynamic capabilities framework. Based on these theoretical foundations and observations from two case studies, we find that EAM can be configured both as a planned, structured capability to support proactive ET, as well as an improvisational, simple capability to support reactive ET under time pressure. We argue that an enterprise can simultaneously deploy both sets of EAM capabilities by identifying the core elements of EAM that are required for both capabilities as well as certain capability-specific extensions. We finally discuss governance and feedback mechanisms that help to balance the goals of flexibility and agility associated with dynamic and improvisational capabilities, respectively.
\end{abstract}

Keywords: Enterprise Transformation, Enterprise Architecture Management, Dynamic Capabilities

\section{Introduction}

Enterprises face an increasingly complex environment which forces them to undergo fundamental change, in other words transform themselves $[1,2]$ The causes for such transformation efforts range from business- or IT-driven initiatives inside the enterprise to external events such as the emergence of new technologies or changing regulatory requirements.

Literature uses different terms to describe fundamental change in the context of organizations, ranging from "organizational transformation" $[3,4]$ or "business transformation" [5] to "enterprise transformation" [1]. While transformation is usually regarded as fundamental, radical change (second-order change) in contrast to smallscale, incremental (first-order) change, there is some discrepancy whether transformation occurs suddenly and purposefully [1,3], or whether it results from a continuum of emergent, smaller changes $[4,6]$. In this paper, we will follow the definition of Rouse [1] and use the term "enterprise transformation" (ET) to describe change that 
fundamentally alters an enterprise's relationship with one of its key constituencies, such as employees, suppliers, customers or investors. We understand ET in contrast to routine change as a purposeful steering intervention into an enterprise's evolution, with its purpose being to respond to perceived opportunities, deficiencies or threats [7].

ET affects multiple domains and layers within an enterprise [8] and is eventually performed simultaneously in different projects, which form the basic unit of change. Since these projects exhibit mutual dependencies, ET needs to be coordinated [9]. In order to support and coordinate ET, the field of enterprise architecture management (EAM) is frequently put forward. EAM is regarded as supporting ET by providing alignment between different partial architectural layers, such as business and information technology (IT) [10]. It is also seen as ensuring coherence of individual projects with the overall enterprise strategy, i.e. aiming for global optimization [11]. Yet, the kind of support required for different ET projects varies. Rouse [1] indicates that ET projects performed as reactions to external pressures (such as competitor's initiatives) lead to higher failure rates than proactive ET projects aimed at exploiting internal or external opportunities. He points out the shorter reaction time in the case of reactive transformation as a cause for this difference in failure rates.

In order to assess EAM support for different types of ET projects, we conducted a focus group with enterprise architects in Switzerland in the fall of 2011. Discussing EAM support of different ET projects, the group arrived at two main findings: (1) EAM is able to support proactive, strategy-driven ET projects when it has positioning on corporate levels instead of IT - a finding that is also reflected in literature [12]. (2) When enterprises need to transform swiftly in response to external pressures, EAM is perceived as being too slow and is often bypassed by the business side.

Especially the second finding indicates that EAM needs to provide its services in a leaner, more responsive way to be actually useful in situations of time pressure. Yet, since enterprises face both types of ET projects [1], EAM needs to support both strategic, proactive change while also being able to provide swift assistance when enterprises are forced to react to external pressures. The research question we intend to answer is the following:

1. RQ: How can EAM be configured into variants that provide specific support for proactive and reactive ET projects?

In this paper, we will take a look at a major framework in strategic management literature that emphasizes changing environments and how enterprises configure their capabilities accordingly: The dynamic capabilities framework. By conceptualizing EAM as one instance of a dynamic capability, we are able to build upon the rich vocabulary and findings from the dynamic capabilities framework, in order to show how the nature of a capability changes in response to different types of environmental dynamics.

The rest of this paper is organized as follows. In chapter 2, we review the foundations of the dynamic capabilities framework and EAM before subsuming EAM under the dynamic capabilities framework. In chapter 3, we show how EAM is able to address different types of environmental change. Chapter 4 provides and compares two 
case studies. Chapter 5 discusses the challenges involved with an EAM function that has to support different configurations. The paper ends with a conclusion.

\section{Foundations}

\subsection{Dynamic Capabilities}

In strategic management literature, the dynamic capabilities framework has become a major topic of research in recent years, with its impact also stretching to the domain of information systems [13].

The ultimate goal of the dynamic capabilities framework is "to explain the sources of enterprise-level competitive advantage over time" [14]. The dynamic capabilities framework can thus be seen as an extension of the resource-based view (RBV), which strives to answer the same question. However, the RBV has been criticized for underestimating environmental dynamics [15]. The RBV takes an inward-looking perspective on enterprises by regarding them as resource bundles. If these resource bundles exhibit the so-called VRIN attributes (i.e., if they are valuable, rare, inimitable and non-substitutable), they are seen as explaining the company's sustained competitive advantage. The dynamic capabilities framework, on the other hand, emphasizes the role of environmental changes: The ability to change existing resource configurations is regarded as the source of sustained competitive advantage. The key argument is that the VRIN attributes of an enterprise's resource bundle erode over time as the environment changes. Superior resource configurations may explain short-term competitive advantage, but to achieve sustainable competitive advantage, dynamic capabilities stress the re-configuration of existing resources in order to achieve and maintain alignment with the environment, i.e. the market $[13,16,17]$.

What the RBV considers as resources, the dynamic capabilities framework sees as operational capabilities, alternatively referred to as "zero-level" [18], "zero-order" or "ordinary" [17] capabilities. Operational capabilities enable firms to make a living by conducting day-to-day business [19]. Collis [20] defines operational capabilities as "those that reflect an ability to perform the basic operational activities of the firm". Concrete examples of operational capabilities are production processes, information and communication infrastructure, sales or marketing functions. These operational capabilities are the object of interest of dynamic capabilities.

In this paper, we will follow the definition of dynamic capabilities provided by Barreto [13] that is based on an extensive literature review on dynamic capabilities research: "A dynamic capability is the firm's potential to systematically solve problems, formed by its propensity to sense opportunities and threats, to make timely and market-oriented decisions, and to change its resource base." This definition indicates the two key processes of a dynamic capability: (1) Search and selection (identifying opportunities and threats and making decisions), and (2) reconfiguration (changing its operational capabilities or resource base). In a similar vein, Teece [14] breaks dynamic capabilities down into "sensing and seizing" and "reconfiguration" capabilities. The definition indicates that dynamic capabilities help enterprises reconfigure their re- 
source base (i.e., their operational capabilities) in a planned, systematic way. This hierarchy is also indicated by the description of dynamic capabilities as "first-order" [17], "reconfiguration" [17] or "higher level" [18] capabilities.

Dynamic capabilities require significant investments in specialized resources and personnel in order to establish and maintain them $[14,18]$. To actually exercise reconfiguration via dynamic capabilities, sufficient time for planning processes and execution is required [16, 17]. Management literature provides various examples of dynamic capabilities, including research and development [19], product development [17], alliancing [16, 19], acquisition [16, 19], knowledge management [14, 19] or activities aimed at "restructuring" [19] or "re-engineering" [19] such as business process management [21].

In order to reconfigure operational capabilities, an enterprise does not necessarily require dynamic capabilities. As Winter [18] notes, "[i]t is quite possible to change without having a dynamic capability". The advantageousness of dynamic capabilities depends on the degree of turbulence in the environment. In relatively stable environments with infrequent changes, occasional reconfiguration can be achieved more costefficiently by "ad hoc problem solving" [18, 19]. Winter [18] defines ad hoc problem solving as individual, spontaneous, and non-repetitive acts of creativity to address suddenly occurring problems. Maintaining dynamic capabilities in these environments may well constitute unnecessary overhead. Reconfiguration of operational capabilities with the help of dynamic capabilities is more advantageous in dynamic environments. In turbulent environments, dynamic capabilities are likely to enable superior performance by providing an institutionalized, planned and patterned approach to changing operational capabilities. As Cohen [22] point out, "fortune favors the prepared firm". The overall degree of stability in the environment is frequently referred to as the level of "environmental turbulence" [17, 23]. Three dimensions of environmental turbulence are proposed [23, 24]:

1. Frequency, as experienced by the time span between environmental changes

2. Amplitude, meaning the degree of difference involved in environmental changes

3. Predictability, meaning the amount to which a pattern is recognizable in environmental changes.

Based on these three dimensions, Eisenhardt and Martin [16] as well as Pavlou and El Sawy [17] distinguish two types of environmental turbulence and their effects on the nature of dynamic capabilities. Table 1 describes these two types.

Table 1. Conceptualization of two types of environmental turbulence

\begin{tabular}{llll}
\hline Type of environmental turbulence & Frequency & Amplitude & Predictability \\
\hline $\begin{array}{l}\text { "Waves" [17], } \\
\text { "Moderately dynamic markets" [16] }\end{array}$ & High & High & High \\
\hline $\begin{array}{l}\text { "Storms" [17], } \\
\text { "High-velocity markets" [16] }\end{array}$ & High & High & Low \\
\hline
\end{tabular}


While both "waves" and "storms" may exhibit high frequencies and amplitudes of change, the important difference lies in the predictability of change. Changes may be frequent and wide-ranging, yet if they occur in a context of stable industry structures, identifiable competitors and clear business models, they still follow a certain pattern and therefore fall in the category of waves [16]. On the other hand, unanticipated market moves by aggressive competitors, shifting and unidentifiable competitors and suddenly changing market needs trigger unpredictable change and thus fall in the category of storms [17].

When environmental turbulence falls into the category of waves, dynamic capabilities are materialized as planned, stable processes that are able to exploit past experiences. However, in the event of storms, dynamic capabilities become simple and emergent activities that rely on improvisation rather than planning [16]. Pavlou and El Sawy [17] introduce the term "improvisational capabilities" in addition, i.e. as complements to dynamic capabilities to describe reconfiguration capabilities that are able to address environmental turbulences marked by unpredictable change (storms). Improvisational capabilities are defined as "the ability to spontaneously reconfigure existing resources to build new operational capabilities to address urgent, unpredictable, and novel environmental situations" [17]. Improvisational capabilities as introduced by Pavlou and El Sawy [17] are explicitly distinguished from Winter's [18] notion of ad hoc problem solving. They are seen as collective, patterned, purposeful and repeated capabilities that can be learned and improved with frequent practice. Pavlou and El Sawy [17] stress the importance of real-time information and communication for improvisational capabilities. On the other hand, too strong a reliance on past knowledge and routines is seen as hindering improvisational capabilities [17] while considered an important element for dynamic capabilities [16]. Given their simpler structure, improvisational capabilities can be exercised considerably faster than dynamic capabilities that often rely on a lengthy planning process [17]. In table 2 , the most important differences between dynamic and improvisational capabilities are summarized.

Table 2. Improvisational vs. dynamic capabilities (based on Pavlou and El Sawy [17])

\begin{tabular}{lll}
\hline $\begin{array}{l}\text { Environmental situa- } \\
\text { tion }\end{array}$ & $\begin{array}{l}\text { Anticipated environmental } \\
\text { events ("waves") }\end{array}$ & $\begin{array}{l}\text { Unprovisational capabilities } \\
\text { events (“storms") }\end{array}$ \\
\hline Nature of activities & Detailed, planned, structured & $\begin{array}{l}\text { Simple, emergent, (largely) un- } \\
\text { structured }\end{array}$ \\
\hline Time requirements & $\begin{array}{l}\text { Sufficient time for formal } \\
\text { planning and execution re- } \\
\text { quired }\end{array}$ & $\begin{array}{l}\text { Faster reconfiguration possible by } \\
\text { enabling spontaneous reactions to } \\
\text { environmental changes }\end{array}$ \\
\hline Role of information & $\begin{array}{l}\text { Heavy reliance on existing } \\
\text { knowledge, memory from past } \\
\text { change projects helps recon- } \\
\text { figuration }\end{array}$ & $\begin{array}{l}\text { Real-time information is critical, } \\
\text { creation of new knowledge }\end{array}$ \\
\hline Proactive ET & Reactive ET \\
\hline
\end{tabular}


Summarizing, both dynamic and improvisational capabilities can be considered instances of first-level reconfiguration capabilities, i.e. they both aim at reconfiguring zero-level operational capabilities. When change is predictable (waves) and can be planned, as in the case of proactive ET, dynamic capabilities are more effective than improvisational capabilities [17, 22]. In unpredictable environments (storms) or reactive ET, when change must be brought about swiftly, improvisational capabilities "fully dominate" [17].

\subsection{Enterprise Architecture Management}

According to the ISO/IEC/IEEE Standard 42010, architecture is defined as "the fundamental organization of a system, embodied in its components, their relationships to each other and the environment, and the principles governing its design and evolution" [25]. This definition of architecture involves two aspects: The first part of the definition ("the fundamental organization of a system, embodied in its components, their relationships to each other and the environment [...]") forms a descriptive aspect, concerning the structure of the system's building blocks and the relationships between them. The second part (" $[\ldots]$ the principles governing its design and evolution") forms a prescriptive aspect, effectively restricting the design and evolution space of the system under consideration.

Following this definition of architecture, we will adopt The Open Group's definition of enterprise architecture (EA) as (1) the fundamental structure of a public or private organization, i.e. a governmental agency or a company, and (2) the principles that guide its design and evolution [26]. Enterprise Architecture Management (EAM) is concerned with establishing, maintaining and purposefully developing an enterprise's architecture [12, 27]. EAM is a continuous management process that addresses EA as its management object [12] and that serves a purpose: achieving business-italignment and supporting ET [12, 28, 29, 30].

Addressing the descriptive aspect of architecture, EAM is concerned with establishing transparency. EAM serves as a decision support function by "taking the overwhelming amount of information available and presenting it in a manner that enables effective decision-making" [31]. Capturing the current state of EA and keeping this information up-to-date is therefore seen as one of the EAM team's core tasks [12].

Concerning the prescriptive aspect of architecture, EAM is concerned with maintaining consistency. Principles guide enterprise evolution by restricting design freedom [32] in order to maintain consistency between the enterprise strategy and its implementation (i.e., the actual EA). In this paper, we will follow the argumentation of Buckl et al. [33] and define architectural principles as either taking the form of guidelines (i.e., recommendations), or restrictions. Standards, on the other hand, provide an operationalization of principles.

The EAM goals of transparency and consistency are not independent: Transparency has to be achieved first, in order to maintain consistency (e.g., to prevent principles on different architectural layers from contradicting each other). Once the goals of transparency and consistency are achieved, the EAM goals of flexibility and agility that support changing an enterprise's architecture can be addressed $[12,30]$. Since 
this paper is concerned with EAM support of ET, we will focus on the goals of flexibility and agility.

\subsection{EAM in the Dynamic Capabilities Framework}

A bundle of dynamic capabilities is required to achieve reconfiguration of operational capabilities. EAM may be seen - amongst several other capabilities as provided in section 2.1-as one specific first-order reconfiguration capability supporting ET. The dynamic capabilities framework stresses the reconfiguration of operational capabilities in order to achieve alignment with the market [13]. EAM stresses the purposeful development (or reconfiguration) of EA building blocks to achieve alignment between architectural layers within the enterprise in order to support transformation [11, 12, 34].

Following a similar argumentation, Aleghehband and Rivard [34] consider "enterprise IT architecture dynamic capability" the "capacity of an organization to purposefully extend, create or modify its IT competencies for tight alignment with the firm's business strategy to support/initiate current/future changes in the business or enable a firm to capitalize on a current/future opportunity." We see the term "enterprise IT architecture" as corresponding to our notion of EAM, since both terms emphasize an enterprise-wide focus with the goal of maintaining alignment between architectural layers: Alaghehband and Rivard [34] stresses that "IT architecture should be analyzed at the enterprise level with the connection to business requirements", citing Ross' [28] definition of enterprise IT architecture as "the organizing logic for applications, data, and infrastructure technologies, as captured in a set of policies and technical choices, intended to enable the firm's business strategy".

The building blocks forming an enterprise's architecture, e.g. its processes, information systems and technical infrastructure, may thus be considered part of its operational capabilities. EAM manages the evolution of EA and thus acts as a reconfiguration capability, depending on the type of environmental turbulence. Figure 1 depicts the conceptualization of EA and EAM in the capabilities framework proposed by Pavlou and El Sawy [17].

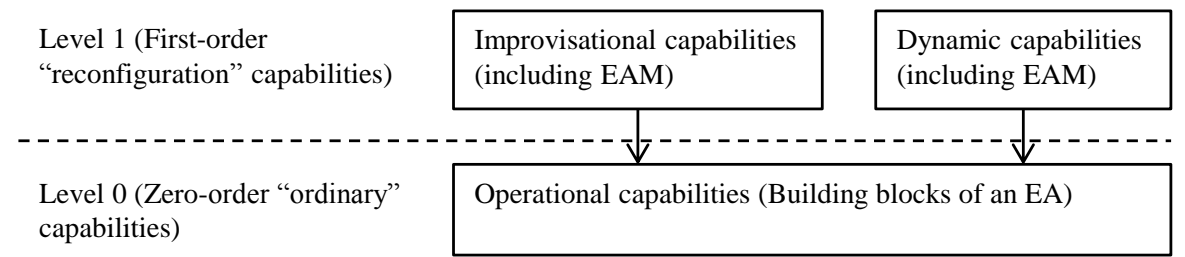

Fig. 1. EA and EAM in the context of ordinary and reconfiguration capabilities (based on Pavlou and El Sawy [17])

Like other dynamic capabilities, establishing and maintaining EAM involves investments that pay off only in environments with a sufficient degree of turbulence. In stable environments with infrequent changes, an enterprise's building blocks could be changed ad hoc, in the sense of Winter's [18] notion of "ad hoc problem solving". 


\section{EAM Capabilities in Environmental Turbulence}

As discussed earlier, the predictability of change is the major determinant whether operational capabilities are to be reconfigured via dynamic capabilities or improvisational capabilities. In the context of EAM, the predictability of change is also distinguishing between two EAM goals: Flexibility and agility [35].

Flexibility is understood as "built-in" configurability, a notion of flexibility also found in production management [36]. In early phases of a design process, a range of possible configurations is determined. The final artifact may then be configured within this pre-considered range. For example, with component based design, end products are configured from individual components, yet the range of components and their configuration rules (which limit the range of possible end products) must be considered at design time. Building configurability into products incurs additional costs; however these initial costs facilitate later changes, since reconfiguration is usually less costly than new development. This is analogous to the situation discussed in dynamic capabilities, which are most advantageous when reacting to frequent yet predictable changes.

In order to address unpredictable changes, i.e. changes that cannot be anticipated at design time, the concept of agility is introduced [35]. Flexibility is considered a subgoal of agility [35, 36], but agility involves, next to adapting to unexpected change, also the dimension of "speed" in the sense of time-to-market [37]. This is especially valuable in highly turbulent environments ("storms"). We therefore see the goal of agility in EAM as analogous to improvisational capabilities.

\subsection{EAM as a Dynamic Capability}

Concerning the descriptive aspect of EA, EAM as a dynamic capability may support planning by providing transparency: Based on as-is models of an enterprise, different to-be models can be derived and discussed in order to arrive at a common vision of the future state of the enterprise. Additionally, the discussion process may be supported by different model analyses such as dependency, coverage or heterogeneity analyses. Finally, a roadmap detailing the planned transition may be derived.

Concerning the prescriptive aspect of EA, existing principles and the standards derived from them may efficiently guide ET. Aier and Schelp [35] see standards as contributing positively to flexibility by increasing the interoperability of EA building blocks (e.g., via the provision of common interfaces). This eventually contributes to the goal of consistency by reducing redundancy and preventing local at the expense of global optimization [11].

A concrete example of EAM in this case would be an insurance company offering customers to buy insurance contracts and manage them online (e.g., report mileage for car insurance or make claims). This would be an example of a planned, proactive ET out of strategic considerations (widen distribution channels). Since this new distribution process involves both existing processes (insurance contracts, claim handling) and existing software systems (existing backend-systems complemented by a new web frontend), EA models and dependency analyses provide important information 
for project management support. Additionally, since the ET is pre-planned, roadmaps, to-be models as well as principles (e.g., on selecting technologies to concentrate know-how or outsourcing to preferred suppliers) can provide support.

\subsection{EAM as an Improvisational Capability}

In the case of unexpected changes, improvisational capabilities involve spontaneous reconfigurations of existing operational capabilities. EAM cannot plan or prescribe improvisational action: It can only aim at providing conditions that support organizational actors' initiative.

Addressing the descriptive aspect of EA, EAM needs to be concerned with transparency as well, yet the focus is on current rather than future information. Pavlou and El Sawy [17] stress the need of real-time information and communication as important foundations of improvisational capabilities. By providing transparency in the form of as-is models, EAM enables a quick assessment of the status quo as the basis for improvisational capabilities. Analyses on as-is models such as dependency and heterogeneity analyses may provide further information input. Additionally, EAM models aim at fostering shared understanding between stakeholders. Since improvisational capabilities are regarded as collective activities, shared understanding as a basis for communication is especially critical. On the other hand, EAM artifacts like to-be models and roadmaps that rely on planning processes and a sufficient time frame are of lesser value in environments of unpredictable change.

In the prescriptive aspect of EA, principles may provide some structure for improvisation, e.g. by coordinating access to resources. Vera and Crossan [38] emphasize the management of existing resources as a foundation for improvisation. However, existing standards are also likely to hinder improvisation by over-restricting design freedom. Literature suggests that relying too much on past knowledge and structures limits creativity and thus hinders improvisation [17, 38]. Pavlou and El Sawy [17] empirically corroborate the importance of real time information and the problem of relying on past knowledge by examining the effect of different IT systems on improvisational capabilities. They conclude that project management systems and collaborative work systems (i.e., systems that focus on transparency and communication) have a significant effect on improvisational capabilities, while organizational memory systems (i.e., systems that store experiences and lessons from past projects) do not. EA standards may be regarded as incorporations of past knowledge, since they are based on past experiences that may no longer be valid. While the intention behind a principle may still be sensible (e.g., to concentrate technological know-how), a concrete standard (e.g., limiting the set of programming languages to be used) may be no longer appropriate. Therefore a feedback loop checking on the validity of standards and eventually principles is important.

Given the shorter time span and the possible side-effects of over-restricting design freedom, EA standards play a less prominent role in improvisational capabilities than in dynamic capabilities. Instead, mechanisms to handle violations of standards need to be in place, in order to circumvent them in a fast yet disciplined way. Thereby, the risk of past knowledge limiting improvisational actions is mitigated, while at the same 
time addressing the issue of implementation speed. Finally, enabling exceptions from standards in a planned way (e.g., merely documenting these exceptions is an important first step) forms the basis for restoring consistency at a later point in time.

Case studies also suggest that active involvement of enterprise architects in projects increases implementation speed $[39,40]$. For example, decision times on architectural issues such as exceptions from standards may be shortened, and project members are provided with a global view of the enterprise (e.g., making them aware of certain dependencies outside project scope). Moreover, the involvement of architects also serves as a feedback loop concerning the validity of principles. While this feature of EAM is likely to provide benefits for both dynamic and improvisational capabilities, the effects on improvisational capabilities are likely to be more pronounced due to the shorter time frames involved.

A scenario for improvisational capabilities would be an insurance company that is forced by upcoming regulations to amend key components of existing contracts (e.g., mandatory unisex rates in health insurance), implying changed risk assessments and changed premiums. While the overall context may be clear early on (laws passed by legislature), the subsequent implementation requirements may be subject to final specification by various regulatory bodies, leaving insurance companies with very little time to react. In this case, having an overview on current EA elements and their dependencies can be critical to achieve regulatory compliance in the short time frame. In order to speed up implementation projects, architects could be assigned to projects in a consulting function. In this role, they can offer advice on existing dependencies beyond the project scope, as well as make quick decisions on overruling general principles and document exceptions.

In table 3, a summary of the configuration of EAM both as a dynamic and improvisational capability is provided.

Table 3. EAM configurations in environmental turbulence

\begin{tabular}{lll}
\hline & Predictable change & Unpredictable change \\
\hline Reconfiguration capabilities & Dynamic capabilities & Improvisational capabilities \\
\hline EAM goal & Flexibility & Agility \\
\hline EA descriptive aspect & Models (As-is, to-be) & As-is models \\
& Analyses & Analyses \\
& Roadmaps & \\
\hline EA prescriptive aspect & Reliance on existing & Exceptions from existing \\
& principles & standards \\
\hline Additional measures & & Active project support by \\
& & enterprise architects \\
\hline
\end{tabular}




\section{$4 \quad$ Case Studies}

\subsection{Company A}

The following case study is reported by Aier and Schelp [35]. Company A is a large telecommunication services provider in Germany. The telecommunication industry is characterized by a high level of environmental turbulence due to a large number of competitors, the unpredictability of their moves and price-sensitive customers. In particular, this leads to frequently changing pricing models, which are-next to the emergence of new technology - the main components of product innovation. Fast time-to-market is vital, especially when Company A has to react to one of its competitor's initiatives. In order to cope with these frequent changes, EAM has been introduced with a focus on technological change projects. Defining an architectural framework has facilitated assessing the impact of change projects. Ultimately, EAM is seen by the management board of Company $\mathrm{A}$ as a change-regulating function to ensure enterprise consistency in a highly dynamic environment.

To provide transparency, Company A has created models on different partial architectures. Model creation and maintenance is still managed locally, but integration into a centralized repository is intended. A main advantage of this integration will be the automated creation of dependency models between artifacts from various partial architectures.

Additionally, principles in the form of technological standards are used to maintain interoperability between the overall architecture and individual change projects. These principles are reviewed bi-annually to ensure continuing relevance. In order to check project results' conformance with architectural principles, Company A has a dedicated review process in place. Assessments are conducted throughout the project phase, so that corrective measures can be invoked quickly. Minor deviations from principles lead to a mitigation plan, consisting of measures to be taken to restore architectural consistency as far as possible. These mitigations have to be financed from the project budget. Major deviations from principles may even lead to project cancellation. Thus, EAM contributes to flexibility by facilitating change within a predefined range.

Furthermore, the company has special exception processes in place for change projects that need to deviate from architectural principles, as may happen in cases of unpredictable and urgent change. In this case, if both a project plan and a budget are defined to eventually restore consistency, exceptions can be granted. If exceptions are granted, all temporary deviations and their rationales are recorded in detail, to enable restoring consistency at a later point. The increase in design freedom has resulted in faster implementation times, and thus contributes to agility. As for restoring consistency, Company A places this responsibility with those projects that originally caused inconsistencies. There are no projects dedicated solely to improving architecture, since all projects at Company A have to define a clear business case.

Architects are also actively involved as consultants in Company A's projects. Company A provides a specific career model for architects, and typically employees in this role have previous experience with consulting-intensive tasks. 


\subsection{Company B}

The following example is taken from Murer's [40] description of the architecture program at Company B, a large Swiss bank. Following a merger, the banking system of the acquired company was being merged into Company B's existing system. This led to a dramatic increase in overall system complexity. Eventually, the new system was no longer able to meet business requirements and suffered from heavy outages. This has led the board of company B to launch an architecture program in order to define a new IT strategy.

Instead of developing a banking system from scratch, it was decided to protect existing assets and invest in the current platform, but to provide stronger governance on the platform's evolution. The board chose an approach called "managed evolution" aimed at swiftly implementing business requirements while at the same time maintaining high levels of system availability and maintainability.

Company B has also created business object and domain models, describing required business functionalities and implementation details across architectural layers (called business, application and technical architecture). A glossary of architectural building blocks is provided in addition to as-is models in order to create a shared vocabulary between different stakeholders. This glossary specifically aims at reducing semantic ambiguity amongst stakeholders from different enterprise domains and has proven very important for shared understanding and maintaining consistency. Company $\mathrm{B}$ also uses to-be models communicating its architectural vision, and roadmaps to describe the transition process.

To evolve towards architectural targets, principles and standards are defined in order to guide system evolution within predefined borders (e.g., restricting the technologies to be used). This reduction of design freedom has increased interoperability between system components and decreased overall system complexity by reducing the number of interfaces to be dealt with. Under the managed evolution approach, projects conducted at Company B fall into one of three categories:

1. New change projects are required to conform to architectural principles if the available time-to-market allows. Projects of this type are considered the normal case at Company B.

2. Company B also has an exception process in place, where business projects are allowed to deviate from existing standards if required time-to-market or business requirements cannot be met within the existing borders of architectural principles. Buckl et al. [33] name the development of a mobile phone app as an example for such deviations, as the required programming language may not be covered by an existing standard limiting language selection.

3. In order to restore architectural consistency, a third type of project is defined which does not implement new business requirements, but aims solely at improving architecture by restoring consistency. Company B dedicates $20 \%$ of its IT budget on CIO level to this purpose [40]. Taking up the previous example, Buckl et al. [33] name a follow-up project replacing the mobile banking application developed inhouse with an off-the-self software complying to a banking standard. 
Finally, in order to anchor the managed evolution approach in the organization, architects are routinely involved as consultants in major projects. Next to bringing architectural expertise and global perspectives into projects, this also speeds up decision times on architectural issues, e.g. exceptions from principles.

\subsection{Comparison of Cases}

Table 4 summarizes and compares EAM as a dynamic or improvisational capability.

Table 4. EAM capabilities in Company A and B

\begin{tabular}{|c|c|c|c|}
\hline $\begin{array}{l}\text { Reconfigura- } \\
\text { tion capability }\end{array}$ & $\begin{array}{l}\text { EA } \\
\text { aspect }\end{array}$ & Company A & Company B \\
\hline \multirow[t]{2}{*}{ Dynamic } & descriptive & $\begin{array}{l}\text { Decentralized models of } \\
\text { partial architectures existing, } \\
\text { integration into centralized } \\
\text { repository pending; } \\
\text { To-be models (scenario } \\
\text { analysis) }\end{array}$ & $\begin{array}{l}\text { As-is models as basis of } \\
\text { shared understanding; Target } \\
\text { architecture is captured in to- } \\
\text { be models; } \\
\text { Roadmaps for transition } \\
\text { planning }\end{array}$ \\
\hline & prescriptive & $\begin{array}{l}\text { Standards to maintain system } \\
\text { interoperability }\end{array}$ & $\begin{array}{l}\text { Projects have to conform to } \\
\text { architectural principles when } \\
\text { time-to-market allows }\end{array}$ \\
\hline \multirow[t]{2}{*}{$\begin{array}{l}\text { Improvisa- } \\
\text { tional }\end{array}$} & descriptive & $\begin{array}{l}\text { Decentralized models of } \\
\text { partial architectures }\end{array}$ & $\begin{array}{l}\text { As-is models as basis of } \\
\text { shared understanding }\end{array}$ \\
\hline & prescriptive & $\begin{array}{l}\text { Exceptions from standards } \\
\text { possible; } \\
\text { Projects are responsible to } \\
\text { restore architectural con- } \\
\text { sistency }\end{array}$ & $\begin{array}{l}\text { Exceptions from standards } \\
\text { possible; } \\
\text { Dedicated CIO budget to } \\
\text { restore architectural con- } \\
\text { sistency }\end{array}$ \\
\hline
\end{tabular}

\section{Discussion}

Enterprises are facing multiple levels of environmental turbulences: They might be able to (1) proactively shape their environment or they might be (2) forced to react to their environment. Therefore, the two extremes-relying exclusively on dynamic capabilities or improvisational capabilities - will lead to inefficient solutions and a loss of competitive advantage in the long run. Instead, enterprises need to reconfigure themselves by using the set of capabilities - dynamic or improvisational - that the level of environmental turbulence favors in a given situation. Enterprises may even have to simultaneously deploy both sets of capabilities in different domains.

In organizational theory, the ability to successfully deploy two apparently competing capabilities is referred to as "ambidexterity". While the interplay between operational and dynamic capabilities is given as one example of an ambidextrous organization [41], improvisational capabilities are introduced as a "third" hand to account for 
the different nature of dynamic capabilities in different types of environmental turbulence [17].

EAM can be regarded as one reconfiguration capability that is adapted (i.e., configured) to support ET in both types of environmental turbulence. This means that an enterprise must be able to execute EAM in two "speeds":

1. as a dynamic capability, providing a complex set of artifacts to support a planned, time-consuming reconfiguration process

2. as an improvisational capability, supporting fast, spontaneous reconfigurations with a simple set of artifacts.

Looking at the EAM instruments supporting both capabilities, we identify a set of basic elements that are required for both dynamic and improvisational capabilities. These basic elements are as-is models and their updating processes, analyses on these models (e.g., on dependencies, heterogeneity) and principles. Configured as a dynamic capability, the set of basic elements is extended with to-be models and roadmaps to support planning, and governance processes using existing principles in order to guide planned changes. Configured as an improvisational capability, the set of basic elements is extended with an exception-handling process to enable swift and creative solutions by deviating from existing principles. Planning-related instruments like tobe models and roadmaps are disregarded in this configuration. The situational EAM configurations are summarized in Fig. 2.

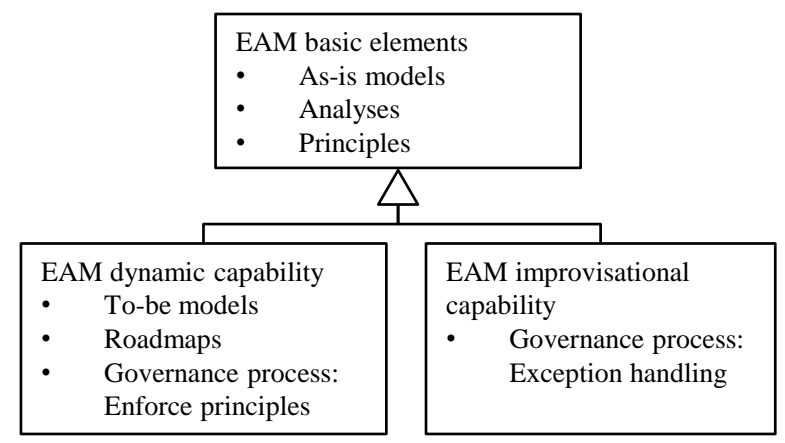

Fig. 2. Situational EAM configuration

While both reconfiguration capabilities exist in enterprises, their goals are competing and need to be balanced. In the case of EAM, this tradeoff is evident between the two goals of flexibility and agility [35]. While flexibility is consistent with the restriction of design freedom, the goal of agility requires greater leeway in reconfiguring operational capabilities. Important enablers of flexibility are standardization and consistency, as these goals provide for efficient reconfiguration within anticipated borders (as expressed via standards and their underlying principles). However, the goal of agility occasionally requires deviations from existing standards and principles and thus introduces inconsistency. 
As the two case studies show, the tradeoff between agility and flexibility can be managed by an exception handling process. This process ensures that deviations from existing principles do not occur in an undocumented way (which would lead to a loss of transparency and into chaotic, ad-hoc problem solving), but in a planned way that enables restoring consistency in the long run. As a major first step, this includes documenting deviations and the associated rationales.

Managing the tradeoff between agility and flexibility and eventually restoring consistency, however, requires governance mechanisms. The two case studies show different mechanisms to govern deviations and their long-term impacts: In Company A, the responsibility for long-term consistency rests with individual change projects: Architectural exceptions are only granted when plans (time/budget) are provided to eventually restore consistency. Company B uses a different approach: centrally allocated budget with the CIO to gradually improve architecture and remove inconsistencies caused by individual projects.

Company A's approach stresses individual project responsibility and thereby puts architectural governance at a local level. This approach bears the risk of consistencyrestoring projects being cancelled, for example as a consequence of management changes at project or super-ordinate levels: New managers may no longer be ready to carry out "repair" projects authorized by their predecessors. Company B's approach, on the other hand, provides centralized governance for architectural issues. This approach mitigates the risk of local managers overriding previous decisions to restore consistency by putting responsibility on a higher organizational level. On the other hand, this approach may also provide a greater incentive for local projects to disregard architectural principles, since the burden to restore consistency is not placed with them, but with a corporate unit. The interplay between dynamic and improvisational capabilities also stresses the importance of feedback mechanisms. If EAM is conducted in a unidirectional way, designed by architects and without the possibility of accounting for feedback of organizational actors, it will not be able to successfully act as any reconfiguration capability. Actors do not only need to use or "read" EA artifacts, they also need to be able to contribute to or "write" EA artifacts.

The EAM goal of transparency mandates updating EA models to reflect changes in the enterprise. These updates cannot be done by architects only in a centralized fashion, as this would in the best case lead to valid, but outdated models. Instead organizational actors have to be provided with feedback channels to forward information on changes in their respective domains to the rest of the enterprise [42]. Only then can EAM provide real-time information and contribute to shared understanding and communication between organizational actors.

In the case of principles, feedback mechanisms are equally important. By providing an exception handling process, feedback from current projects continuously challenges the validity of existing principles. This feedback can be further improved and sped up by actively involving architects in ET projects, e.g. as consultants. This scrutiny enables the ongoing refinement and validation of principles and standards- - to check if the given design restrictions are still aligned with environmental demands.

Summing up our findings, we conclude with two propositions: 
1. As a dynamic capability, EAM is concerned with both descriptive and prescriptive aspects of EA, while as an improvisational capability, EAM is concerned mostly with the descriptive EA aspects.

2. In order to deploy EAM as a dynamic or an improvisational capability, governance and feedback mechanisms are critical.

\section{Conclusion}

In this paper, we have conceptualized EAM as a capability within the dynamic capabilities framework. This framework stresses the different nature of reconfiguration capabilities based on the predictability of environmental change. Transferring these findings onto EAM, we have derived two propositions showing (1) which EA artifacts support which reconfiguration capability and (2) the mechanisms involved in alternating between the two reconfiguration capabilities or speeds of EAM, namely governance and feedback.

This distinction is the main contribution of our paper, as it shows how EAM is capable of supporting both proactive and reactive ET. The main limitation of our work is the small number of case studies: Further empirical data, focusing specifically on EAM being deployed as a dynamic or an improvisational capability, are required to improve our understanding of EAM switching between these two reconfiguration capabilities.

While this paper provides a first classification of the building blocks required for each capability, this specification needs to be worked out in greater detail in future work. Future research efforts are also needed to better understand the effects and possible designs of different EAM governance and feedback mechanisms. Especially the idea of feedback loops, with the goal of making EAM accessible to and encouraging participation from a wide audience of stakeholders seems an important research direction.

\section{Acknowledgement}

This work has been supported by the Swiss National Science Foundation (SNSF).

\section{References}

1. Rouse, W.B.: A Theory of Enterprise Transformation. Systems Engineering 8:4, 279-295 (2005)

2. Purchase, V., Parry, G., Valerdi, R., Nightingale, D., Mills, J.: Enterprise Transformation: Why Are We Interested, What Is It, and What Are the Challenges? Journal of Enterprise Transformation 1:1, 14-33 (2011)

3. Romanelli, E., Tushman, M.L.: Organizational Transformation as Punctuated Equilibrium: An Empirical Test. Academy Of Management Journal 37:5, 1141-1166 (1994)

4. Orlikowski, W.J.: Improvising Organizational Transformation Over Time: A Situated Change Perspective. Information Systems Research 7:1, 63-92 (1996) 
5. Safrudin, N., Recker, Jan, Rosemann, Michael: The Emerging Management Services Of Business Transformation Management. In: PACIS 2011 Proceedings. Paper 160. (2011)

6. Beer, M., Eisenstat, R.A., Spector, B.: Why Change Programs Don't Produce Change. Harvard Business Review 68:6, 195-198 (1990)

7. Rouse, W.B., Baba, M.L.: Enterprise transformation. Communications Of The ACM 49:7, 67-72 (2006)

8. Rouse, W.B.: Enterprises as systems: Essential challenges and approaches to transformation. Systems Engineering 8:2, 138-150 (2005)

9. Malone, T.W., Crowston, K.: The Interdisciplinary Study of Coordination. ACM Computing Surveys 26:1, 87-119 (1994)

10. Henderson, J.C., Venkatraman, N.: Strategic alignment: Leveraging information technology for transforming organizations. IBM Systems Journal 32:1, 4-16 (1993)

11. Foorthuis, R., van Steenbergen, M., Mushkudiani, N., Bruls, W., Brinkkemper, S., and Bos, R.: On Course, but Not There Yet: Enterprise Architecture Conformance and Benefits in Systems Development. In: ICIS 2010 Proceedings. Paper 110. (2010)

12. Radeke, F.: Toward Understanding Enterprise Architecture Management's Role in Strategic Change: Antecedents, Processes, Outcomes. In: Proceedings of the 10th International Conference on Wirtschaftsinformatik WI 2.011, pp. 497-507 (2011)

13. Barreto, I.: Dynamic Capabilities: A Review of Past Research and an Agenda for the Future. Journal Of Management 36:1, 256-280 (2010)

14. Teece, D.J.: Explicating dynamic capabilities: the nature and microfoundations of (sustainable) enterprise performance. Strategic Management Journal 28:13, 1319-1350 (2007)

15. D'Aveni, R.A.: Hypercompetition: Managing the Dynamics of Strategic Management. Free Press, New York (1994)

16. Eisenhardt, K.M., Martin, J.A.: Dynamic Capabilities: What are They? Strategic Management Journal 21:10/11, 1105-1121 (2000)

17. Pavlou, P.A., El Sawy, O.A.: The "Third Hand": IT-Enabled Competitive Advantage in Turbulence Through Improvisational Capabilities. Information Systems Research 21:3, 443$471(2010)$

18. Winter, S.G.: Understanding dynamic capabilities. Strategic Management Journal 24:10, 991-995 (2003)

19. Zollo, M., Winter, S.G.: Deliberate Learning and the Evolution of Dynamic Capabilities. Organization Science 13:3, 339-351 (2002)

20. Collis, D.J.: Research note: How valuable are organizational capabilities? Strategic Management Journal 15:SPECIAL ISSUE, 143-152 (1994)

21. Niehaves, B., Plattfaut, R., Becker, J.: Does Your Business Process Management (Still) Fit the Market? - A Dynamic Capability Perspective on BPM Strategy Development. In: AMCIS 2010 Proceedings. Paper 292. (2010)

22. Cohen, W.M., Levinthal, D.A.: Fortune Favors the Prepared Firm. Management Science 40:2, 227-251 (1994)

23. Wholey, D.R., Brittain, J.: Characterizing Environmental Variation. The Academy of Management Journal 32:4, 867-882 (1989)

24. Child, J.: Organizational Structure, Environment and Performance: The Role of Strategic Choice. Sociology 6:1, 1-22 (1972)

25. ISO/IEC/IEEE: Systems and software engineering -- Architecture description (ISO/IEC/IEEE 42010:2011) (2011)

26. The Open Group: TOGAF Version 9.1 (2011) 
27. Aier, S., Gleichauf, B., Winter, R.: Understanding Enterprise Architecture Management Design - An Empirical Analysis. In: Proceedings of the 10th International Conference on Wirtschaftsinformatik WI 2.011, pp. 645-654, Zurich (2011)

28. Ross, J.W.: Creating a strategic IT architecture competency: Learning in stages. MIS Quarterly Executive 2:1, 31-43 (2003)

29. Rohloff, M.: Integrating Innovation into Enterprise Architecture Management. In: Proceedings of the 10th International Conference on Wirtschaftsinformatik WI 2.011, pp. 776-786 (2011)

30. Tamm, T., Seddon, P.B., Shanks, G., Reynolds, P.: How Does Enterprise Architecture Add Value to Organisations? Communications Of The Association For Information Systems 28, 141-168 (2011)

31. Strano, C., Rehmani, Q.: The Role of the Enterprise Architect. International Journal of Information Systems and e-Business Management 5:4, 379-396 (2007)

32. Dietz, J.L.G., Hoogervorst, J.A.P.: Enterprise ontology in enterprise engineering. In: Proceedings of the 2008 ACM Symposium on Applied Computing, Fortaleza, Ceara, Brazil (2008)

33. Buckl, S., Matthes, F., Roth, S., Schulz, C., Schweda, C.M.: A Conceptual Framework for Enterprise Architecture Design. In: 5th International Workshop on Trends in Enterprise Architecture Research (TEAR 2010), pp. 44-56. Springer, Delft (2010)

34. Alaghehband, F.K., Rivard, S.: The Strategic Role of Information Technology Sourcing: A Dynamic Capabilities Perspective. In: ICIS 2010 Proceedings. Paper 107. (2010)

35. Aier, S., Schelp, J.: How to Preserve Agility in Service Oriented Architectures - An Explorative Analysis. Enterprise Modelling And Information Systems Architectures 5:2, 21-37 (2010)

36. Yusuf, Y.Y., Sarhadi, M., Gunasekaran, A.: Agile manufacturing: the drivers, concepts and attributes. International Journal Of Production Economics 62:1-2, 33-43 (1999)

37. Sambamurthy, V., Bharadwaj, A., Grover, V.: Shaping Agility through Digital Options: Reconceptualizing the Role of Information Technology in Contemporary Firms. MIS Quarterly 27:2, 237-263 (2003)

38. Vera, D., Crossan, M.: Improvisation and Innovative Performance in Teams. Organization Science 16:3, 203-224 (2005)

39. Hafner, M., Winter, R.: Processes for Enterprise Application Architecture Management. In: Proceedings of the 41st Annual Hawaii International Conference on System Sciences (HICSS'41), pp. 396 (391--310). IEEE Computer Society (2008)

40. Murer, S., Bonati, B., Furrer, F.J.: Managed Evolution: A Strategy for Very Large Information Systems. Springer, Heidelberg (2010)

41. Pavlou, P.A., El Sawy, O.A.: From IT competence to competitive advantage in turbulent environments: The case of new product development. Information Systems Research 17:3, 198-227 (2006)

42. Castela, N., Zacarias, M., Tribolet, J.: PROASIS: As-Is Business Process Model Maintenance. In: Harmsen, F., Grahlmann, K., Proper, E. (eds.): Practice-Driven Research on Enterprise Transformation, pp. 53-82. Springer Berlin Heidelberg (2011) 